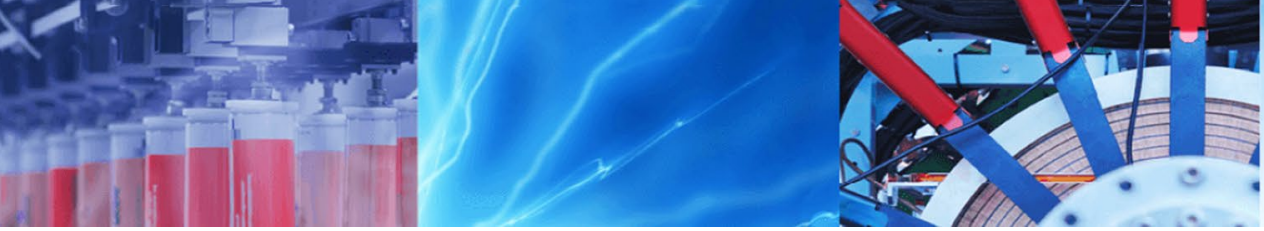

Research Article

\title{
A goal programming model for grid-connected hybrid energy system operations
}

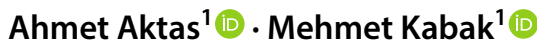

Received: 4 October 2019 / Accepted: 9 December 2019 / Published online: 12 December 2019

(c) Springer Nature Switzerland AG 2019

\begin{abstract}
Hybrid energy systems are considered as a potential solution for sustainable energy supply for small and medium scaled energy networks. This kind of energy systems consist of different type of conventional and renewable resources and classified into two groups, stand-alone and grid-connected systems. To see benefits of hybrid energy systems, making operational decisions analytically is extremely important. The main aim of this study is to determine operational decisions of a hybrid energy system by considering profit obtained by system operations and renewable energy utilization ratio in load demand satisfaction. To solve the mathematical model of this multi-objective optimization problem, a goal programming model is proposed in this study. A numerical example for a small town with 10 demand points and 4 energy generation plants is presented to demonstrate the applicability of the proposed model. Electricity demand in the small town is satisfied by energy generation plants and grid-connection. Obtained results show that the proposed model can be used by investors to analyze profitability of the system and renewable energy utilization ratio in the region.
\end{abstract}

Keywords Hybrid energy system · Goal programming · Renewable energy · Sustainability · Linear programming · Multiobjective optimization

Mathematics Subject Classification $90 \mathrm{C} 29 \cdot 90 \mathrm{C} 05$

JEL Classification $\mathrm{C} 61 \cdot \mathrm{Q} 42$

\section{Introduction}

Energy is an important part of human life. Energy is used in many daily activities such as transportation, production, heating, cooling, cooking, etc. [1]. However, most of the existing energy resources are expected to be depleted in a very close future due to the rapid progress of industrialization and increasing population. Because of the remained short time for depletion of energy resources, new resources for energy generation are being searched. Renewable resources are accepted to be one of the most promising energy generation ways [2].
Renewable energy is the energy obtained by regenerative processes [3]. Solar energy, wind energy and geothermal energy are some types of renewable energy resources [4]. Renewables are useful for generating clean energy in an economic manner. Utilization of renewable energy gets more common, because these resources are environmentally friendly and inexhaustible resources. On the other hand, they are commonly variable according to climate conditions. This disadvantage leads the concept of hybrid renewable energy systems. Hybrid renewable energy systems are defined as energy systems with combination of renewable energy resources and/or conventional energy resources. Construction of hybrid energy systems is useful

Ahmet Aktas, aaktas@gazi.edu.tr | 1 Department of Industrial Engineering, Gazi University, 06570 Ankara, Turkey. 
for sustainable energy supply from renewable resources. Since, renewable energy resources are generally variable due to the climate conditions, some problems may occur at satisfying energy demand from renewable resources in large scale energy systems. Some of these problems are energy fluctuations, supply shortages, and low quality of energy.

Hybrid energy systems are classified into stand-alone and grid-connected classes [5]. In stand-alone systems, generated and stored energy is used for demand satisfaction. On the other hand, grid-connected systems can utilize help of grid-connection in order to satisfy shortened demand.

Optimization of system activities is required in order to see benefits of hybrid energy systems completely. Optimization of such systems are computationally hard because of existence of number of parameters to be considered. Moreover, to analyze effects of seasonal and daily changes on the system, optimization must be done at least for a year period and at least hourly detail level.

In this study, operational decisions of a hybrid energy system in a province is analyzed. Investor is looking for the best operation strategy, which provides the maximum profit. Moreover, there is a desired level for renewable energy utilization rate in 2023 Targets of Turkish Ministry of Energy and Natural Resources. The main aim of this study is to obtain a compromise solution between desired profit of investor and renewable energy utilization rate target of country. To do so, a goal programming model is proposed to determine the best operational strategy for electricity demand satisfaction in the hybrid energy network of a province with an example.

The rest of the paper is organized as follows: The Second Part consists a summary of recent literature on optimization problems on hybrid energy systems. Problem description and mathematical formulation of the proposed goal programming model are expressed in the Third part. Data and results of the numerical example are presented with solution results in the Fourth Part. The study is concluded in the Fifth Part by giving managerial implications and future research suggestions.

\section{Literature review}

Optimization of hybrid energy systems have taken attention of researchers. Hybrid energy system of a poor rural community was analyzed by using HOMER (Hybrid Optimization Model for Electric Renewable) software [6]. Combination of wind, photovoltaic and battery options were analyzed. Reliability concern for energy supply of a wind farm in Iran was supported by hybridization with biomass energy [7]. Techno-economic evaluation of system was made by using meteorological data. Energy management of a hybrid railway power substation system for a planning horizon of 1 year with hourly time steps was supported by a simulation model [8]. Power balance and economics of the system was optimized by using a linear formulation. Technical comparison of a hybrid solar water heater and electric storage tank water heater was presented in Hohne et al.'s study [9]. A life cycle cost analysis was also presented in their study with break-even point calculation for the hybrid solar water heating system. Bento et al. [10] proposed an optimized control strategy for hybrid energy systems which contains photovoltaics, pumped-storage hydropower, and wind power under different scenarios. A hybrid energy system with grid-connection in Mali was optimized using HOMER software [11]. Integration of photovoltaics into energy system made emission decrease of carbon dioxide emitted by thermal plants.

Gonzalez et al. [12] developed a multi-objective genetic algorithm for environmental and cost optimization of a hybrid electricity generation system which consists of biomass, photovoltaics and wind resources. Konneh et al. [13] used multi-objective particle swarm optimization approach to determine sizing decisions of a hybrid energy system with photovoltaic panels, wind turbines and biomass combustion plant in Sierra Leone in views of four objective functions. Fuzzy chance constraint programming is used to determine optimal capacities of power generation and energy storage units under system reliability constraint [14].

As it can be seen from the recent literature, different decision problems on hybrid energy systems are faced and researches to solve them are conducted. In this study, optimization of operating decisions of a grid connected solar energy system is considered.

\section{Proposed model}

This study proposes a goal programming model for a hybrid energy system. Goal programming is a commonly used approach to obtain compromise solutions to multiobjective optimization models and details of goal programming model can be seen in [15]. This system is represented as a network with possible supply resources and demand points in a province and consists of renewable energy resources and grid-connection. Grid-connection is used when renewables supply inadequate amount of electricity. The main aim of this model to determine a compromise operational strategy that satisfies electricity demand at minimum total deviation from desired profit level and renewable energy utilization rate. Mathematical formulation of the model presented as follows: 
Indices

i Energy generation plants

j Demand points

$\mathrm{t}$ Planning periods.

\section{Parameters}

$$
\sum_{i} X_{i j t} \geq D_{j t} * f_{j t} \quad \forall j, t
$$$$
X S_{j t} \leq M *\left(1-f_{j t}\right) \quad \forall j, t
$$$$
\sum_{j} X_{i j t} \leq \operatorname{cap}_{i t} \times Y_{i t} \quad \forall i, t
$$

cap $_{\text {it }} \quad$ Electricity generation capacity of plant $i$ in period $t$.

$$
X_{i j t} \geq 0 \quad \forall i, j, t
$$

\section{Decision variables}

$X_{i j t} \quad$ Transmitted electricity amount from plant $i$ to point $j$ in period $t$

$X S_{j t} \quad$ Purchased electricity amount from grid for demand satisfaction at point $j$ in period $t$

$R U_{t} \quad$ Renewable energy utilization rate in period $t$.

$$
X S_{j t} \geq 0 \quad \forall j, t
$$

$$
R U_{t} \geq 0 \quad \forall t
$$

$Y_{i t} \in\{0,1\} \quad \forall i, t$

$Y_{i t}=\left\{\begin{array}{l}1, \text { if plant } i \text { is used for energy generation in period } t \\ 0, \text { otherwise }\end{array} \quad Q_{i} \in\{0,1\} \quad \forall i, t\right.$

$f_{j t}=\left\{\begin{array}{l}1, \text { if electricity demand of point } j \text { is satisfied by renewables in period } t \\ 0, \text { otherwise }\end{array}\right.$

$Q_{i}=\left\{\begin{array}{l}1, \text { if plant } i \text { is used for energy generation during the planning period } \\ 0, \text { otherwise }\end{array}\right.$

\section{Mathematical model}

$\min d_{1}^{-}+d_{2}^{-}$

$\sum_{t} \sum_{i} \sum_{j} s p_{i} X_{i j t}-\sum_{i} \sum_{j} \sum_{t} c_{i j} X_{i j t}-\sum_{i} A_{i} Q_{i}+d_{1}^{-}-d_{1}^{+}=P$

$\sum_{t} R U_{t} / T+d_{2}^{-}-d_{2}^{+}=R$

$\sum_{i} X_{i j t}+X S_{j t} \geq D_{j t} \quad \forall j, t$

$$
f_{j t} \in\{0,1\} \quad \forall i, t
$$

Equation (1) is the objective function of the model. Objective of the goal programming model is to minimize total deviation from aspiration levels of goal constraints. Equations (2) and (3) represents the goal constraints of the model, respectively. The former expresses the profit goal and the latter expresses the average renewable energy utilization rate goal. Equation (4) states that the demand for electricity will be satisfied by renewable resources and grid connection. Equations (5) and (6) show that the renewables are primarily used for satisfying demand and if the supply of renewables are inadequate, grid supply is used. Equation (7) defines the renewable energy plant generation capacity. Renewable energy utilization rate is calculated by Eq. (8). Equation (9) states that fixed costs for plants is applied if they are used for energy generation at 
Residential Demand Curve
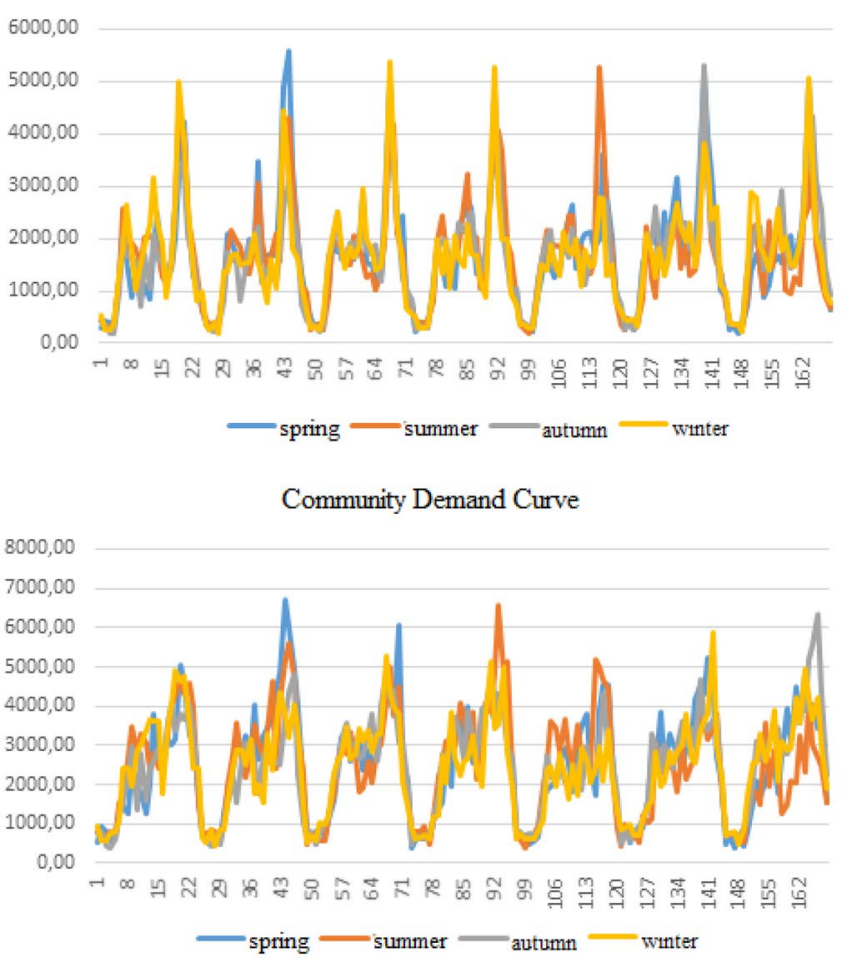

Fig. 1 Demand characteristics of demand points

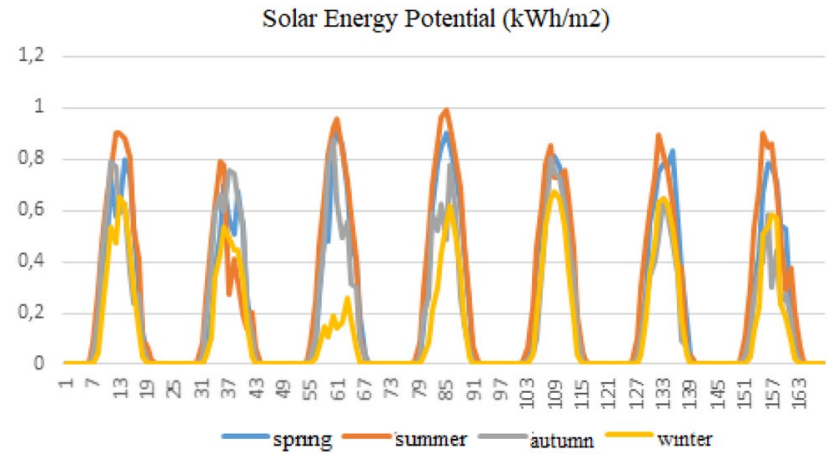

Fig. 2 Solar energy potential

least one period. Equations (10)-(15) are the sign restrictions for decision variables.

\section{Numerical example}

The proposed model is solved for a small scale energy network with 10 demand points and 2 energy generation plants. To represent seasonal and hourly variation of supply and demand characteristics, 1-week data for each season is considered. So, a planning period of $672 \mathrm{~h}$ is determined. Values for model parameters are taken from some
Commercial Demand Curve
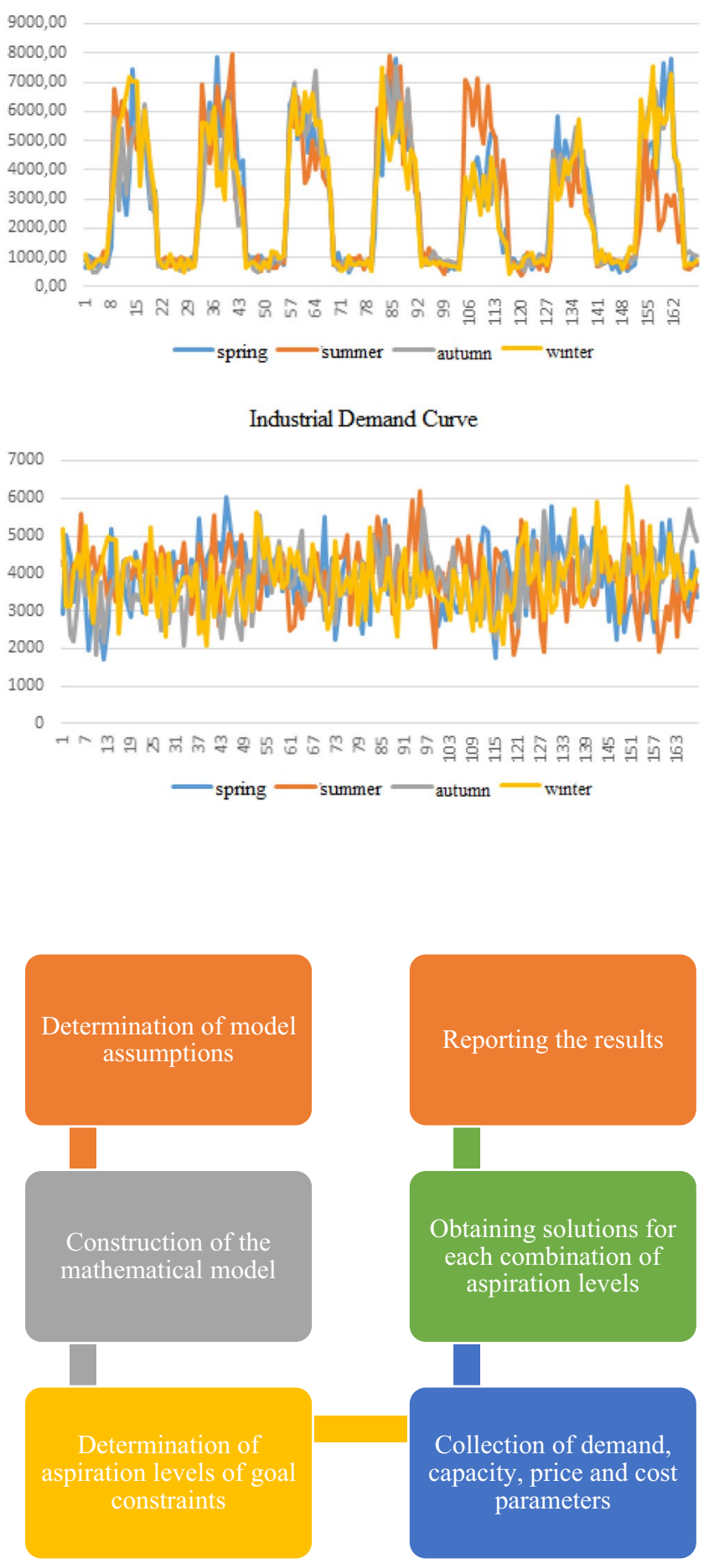

Fig. 3 Flowchart for solution process

studies in the literature and capacity and demand values are taken from HOMER software. Supply and demand characteristics are presented in Figs. 1 and 2. Parameter values are determined as $\mathrm{sp}_{\mathrm{i}}=13.3 \mathrm{cent} / \mathrm{kWh}, \mathrm{c}_{\mathrm{ij}}=0.0632 \$ /$ $k W h+0.0001 \$ \times d_{i j}$ and $A_{i}=18,000 \$$. Flowchart of the solution process is given in Fig. 3 . 
Table 1 Solution results

\begin{tabular}{lrlll}
\hline Case & $P$ value & R value & $d_{1}^{-}$value & $d_{2}^{-}$value \\
\hline 1 & 50,000 & 0.205 & 0 & 0.129 \\
2 & 100,000 & 0.205 & 0 & 0.101 \\
3 & 150,000 & 0.205 & 0 & 0.065 \\
4 & 200,000 & 0.205 & $41,381.76$ & 0.059 \\
5 & 250,000 & 0.205 & $94,165.70$ & 0.061 \\
\hline
\end{tabular}

Goal programming model is run by using CPLEX solver of GAMS software on a PC with Intel Core $^{\mathrm{TM}}$ i5-6500T processor and 8 GB RAM. Desired renewable energy utilization rate value $(\mathrm{R})$ is determined as 0.205 , which is the official target of Turkish Republic. To investigate the effect of desired profit value on solution, the model is run by assuming that $P$ value is equal to $50,000 \$, 100,000 \$, 150,000 \$, 200,000 \$$, and $250,000 \$$. Solution results of five cases are presented in Table 1.

Solution results show that under these capacity, cost and selling price values, an operating policy satisfying desired renewable energy utilization rate cannot be obtained. However, adding more plants into hybrid energy system can provide desired results. Furthermore, increase of aspiration level of profit returns solutions with deviation. Desired profit values can be predicted according to this analysis.

Obtaining a compromise solution by using the goal programming model demonstrates that the model can be used for determination of operational decisions in hybrid energy networks.

\section{Conclusion}

In this study, a goal programming model is proposed for determining the optimal operating decisions in a hybrid energy system. A numerical example is solved by considering different values of desired value on profit goal.

The main limitation of the model is consideration of a $672 \mathrm{~h}$ planning period. A longer period horizon may present more detailed solutions. Since this model only considers energy demand satisfaction, extension of the model by considering also the thermal energy demand can be developed in the future. Moreover, using different multi-objective optimization techniques and comparison of obtained results with evolutionary optimization algorithms for greater problem dimensions can be analyzed in further studies. Another extension of this study is the verification of obtained results with this model on a real world data set.

\section{Compliance with ethical standards}

Conflict of interest On behalf of all authors, the corresponding author states that there is no conflict of interest.

\section{References}

1. Aktas A, Kabak M (2019) A hybrid hesitant fuzzy decision-making approach for evaluating solar power plant location sites. Arab J Sci Eng 44:7235-7247. https://doi.org/10.1007/s1336 9-018-3604-5

2. Panwar NL, Kaushik SC, Kothari S (2011) Role of renewable energy sources in environmental protection: a review. Renew Sustain Energy Rev 15(3):1513-1524. https://doi.org/10.1016/j. rser.2010.11.037

3. Louhi JT (2007) Energy efficiency of modern cellular base stations. In: INTELEC 07-29th international telecommunications energy conference, Rome, pp 475-476. https://doi.org/10.1109/ INTLEC.2007.4448824

4. Büyüközkan G, Güleryüz S (2017) Evaluation of renewable energy resources in Turkey using an integrated MCDM approach with linguistic interval fuzzy preference relations. Energy 123:149-163. https://doi.org/10.1016/j.energy.2017.01.137

5. Kaundinya DP, Balachandra P, Ravindranath NH (2009) Gridconnected versus stand-alone energy systems for decentralized power-a review of literature. Renew Sust Energ Rev 13:20412050. https://doi.org/10.1016/j.rser.2009.02.002

6. Krishan O, Suhag S (2019) Techno-economic analysis of a hybrid renewable energy system for an energy poor rural community. J Energy Storage 23:305-319

7. Tajeddin A, Roohi E (2019) Designing a reliable wind farm through hybridization with biomass energy. Appl Therm Eng 154:171-179

8. Yang N, Pouget J, Letrouvé T, Jecu C, Joseph-Auguste L (2019) Techno-economic design methodology of hybrid energy systems connected to electrical grid: an application of hybrid railway power substation. Math Comput Simul 158:107-119

9. Hohne PA, Kusakana K, Numbi BP (2019) Optimal energy management and economic analysis of a grid-connected hybrid solar water heating system: a case of Bloemfontein, South Africa. Sustain Energy Technol 31:273-291

10. Bento P, Nunes H, Pombo J, Calado MdR, Mariano S (2019) Daily operation optimization of a hybrid energy system considering a short-term electricity price forecast scheme. Energies 12:924-948

11. Touré $A F$, Addouche $S A$, Danioko F, Diourté B, El Mhamedi A (2019) Hybrid systems optimization: application to hybrid systems photovoltaic connected to grid. A Mali case study. Sustainability 11:2356-2375

12. Gonzalez A, Riba JR, Esteban B, Rius A (2018) Environmental and cost optimal design of a biomass-Wind-PV electricity generation system. Renew Energy 126:420-430

13. Konneh DA, Howlader HOR, Shigenobu R, Senjyu T, Chakraborty S, Krishna N (2019) A multi-criteria decision maker for gridconnected hybrid renewable energy systems selection using multi-objective particle swarm optimization. Sustainability 11:1188-1223

14. Lee JY, Aviso KB, Tan RR (2019) Multi-objective optimisation of hybrid power systems under uncertainties. Energy 175:1271-1282

15. Uzun G, Dağdeviren M, Kabak M (2016) Determining the distribution of coast guard vessels. Interfaces 46:297-314

Publisher's Note Springer Nature remains neutral with regard to jurisdictional claims in published maps and institutional affiliations. 